\title{
Corpo, cognição e vontade: aproximação e distanciamento entre Schopenhauer e a teoria enativista
}

\author{
Body, cognition and will: rapprochement and detachment between \\ Schopenhauer and enactivist theory
}

\author{
André Henrique Mendes Viana de Oliveira \\ Doutorando em Filosofia pela UFC \\ Professor de Filosofia do IFPI \\ E-mail: andylantista@gmail.com
}

\begin{abstract}
Resumo: 0 presente artigo esboça uma discussão a respeito do problema mente-corpo a partir de um confronto entre a metafísica da Vontade de Schopenhauer e a teoria enativista. Apresentaremos a tese schopenhaueriana da primazia da vontade sobre o intelecto e, em seguida, a relação entre vida e mente de acordo com as noções de autopoiesis e autonomia adaptativa da teoria enativista. Nosso propósito central será o de apontar um possível diálogo entre as duas propostas teóricas, tomando como ponto comum a crítica a um conceito tradicional de cognição.
\end{abstract}

Palavras-chave: Autopoiesis; Cognitivismo; Corpo; Vontade.
Abstract: This paper sketches a discussion about the mind-body problem from a confrontation between Schopenhauer's metaphysics of Will and enactivist theory. We show schopenhauerian thesis about primacy of will on intellect, and then the relationship between life and mind accordingly the notions of autopoiesis and adaptative autonomy of enactivist theory. Our main aim is to point out a possible dialogue between two theoretical purposes taking as common point the criticism of a traditional concept of cognition.

Keywords: Autopoiesis; Cognitivism; Body; Will. 
$\mathrm{N}$ o hodierno contexto em que a filosofia da mente tem alcançado um grande espaço, um dos problemas mais investigados tem sido o da relação entre mente e cérebro, problema este que, conquanto seja discutido à luz de novas teorias e analisado com o auxílio de novos métodos e recursos, relaciona-se de um modo geral com problemas clássicos da filosofia. Podemos apontar, por exemplo, uma relação entre o problema mente-cérebro e o antigo dualismo almacorpo, que engendrou uma rica discussão no âmbito da literatura filosófica, sobretudo a partir do período moderno, quando Descartes instaura, com o cogito ergo sum, a consciência como via de acesso à distinção radical entre substância extensa e substância pensante, abrindo caminho para uma interpretação da alma como substância.

De modo geral, o problema mente-cérebro é ainda muito repercutido sob uma suposta contraposição entre estados mentais ditos conscientes, atribuíveis ao sujeito dotado da faculdade racional, e uma gama de outros estados, não-conscientes, que estariam ligados à constituição fisiológica do cérebro, contraposição esta que nos remete se não a um dualismo de substâncias de matriz cartesiana, ao menos a um dualismo de propriedades $^{1}$.

As diversas correntes teóricas que compõem o debate contemporâneo, ao por em xeque a pretensa separação radical entre substância imaterial e substância material, vem propondo diferentes enquadramentos no que diz respeito à relação entre nossa faculdade consciente e os eventos não-conscientes que nos ocorrem ${ }^{2}$. Pode-se afirmar, de um modo mais específico, que a tese de que nossa alma (ou nossa mente, em termos atuais) não constitui uma substância independente do corpo é reconhecível já no pensamento de Arthur Schopenhauer, sobretudo no segundo volume de $O$ mundo como vontade e como representação, onde o filósofo aprofunda suas teses a respeito da relação entre nossas funções cerebrais e nossa natureza volitiva.

Também em sua última obra, Parerga e paralipomena, Schopenhauer reprova a tese de que "o cognoscente em nós é uma substância imaterial radicalmente diferente do corpo, chamada alma"3 ${ }^{3}$ Constitui parte da tese metafísica basilar do filósofo a asserção de que o corpo, considerado no conjunto de suas funções biológicas, configura-se como o

\footnotetext{
${ }^{1}$ De acordo com a corrente teórica conhecida como dualismo de propriedades, a mente (estados subjetivos) e o cérebro (físico) constituiriam duas propriedades distintas irredutíveis uma à outra.

${ }^{2} \mathrm{O}$ behaviorismo filosófico, a teoria da identidade, o funcionalismo, o eliminativismo e o dualismo de propriedades constituem exemplos de tais correntes.

${ }^{3}$ SCHOPENHAUER, A. P/P, § 4, p. 78, tradução nossa.

Corpo, cognição e vontade: aproximação e distanciamento entre Schopenhauer e a teoria enativista
} 
objeto primordial para o conhecimento do mundo. Isto porque, de acordo com ele, a intuição de nosso próprio corpo revela a vontade, e esta é concebida como um princípio metafísico que possui uma quase absoluta primazia sobre nossa faculdade cognoscente ${ }^{4}$, sobre nossa consciência. Assim, para ele:

Sem a intuição mediada pelo corpo, o conhecimento carece de matéria; e, portanto, o cognoscente enquanto tal, sem a suposição do corpo, não é mais que uma forma vazia; sem falar que todo pensamento é uma função fisiológica do cérebro, como a digestão o é do estômago 5 .

Safranski observa que, ao encontrar no próprio corpo uma resposta metafísica, Schopenhauer não nos remete a um autoconhecimento no sentido moral tradicional, tampouco endossa a ideia de autoconhecimento comum à filosofia reflexiva, antes procura "transformar a experiência da vontade agindo no interior de seu próprio corpo em um meio para compreender essa totalidade do mundo" ${ }^{6}$. Assim, o corpo enquanto objetidade da Vontade (Objektität des Willens) é condição para a representação, dado que sem ele nenhuma representação, ou, poderíamos dizer, nenhum mundo, nos seria possível. Sua constituição orgânica e funcional, incluindo o próprio órgão que nos apresenta o mundo tal como o percebemos, isto é, o cérebro, é o que permite a representação, "pois o mundo real dos corpos é antes de tudo apenas representação intuitiva e como tal fenômeno cerebral"7. A vontade se apresenta ao indivíduo através do seu próprio corpo como uma força de ordem metafísica que o anima e que mantém aceso o pulso da vida até seu último lampejo. Como um sopro que fizesse iniciar o funcionamento de todos os órgãos, a vontade é a base da qual dependem todos eles, "Ao contrário, a índole da vontade não depende de e nem pode ser prognosticada por órgão algum"8. Assim Schopenhauer aponta a função do conceito de Vontade em sua metafísica:

Que a vontade que encontramos em nosso interior não procede, antes de tudo, como a filosofia até agora admitiu, do conhecimento, nem é uma mera modificação deste, logo, não é secundária e derivada, nem, como o

\footnotetext{
${ }^{4}$ No artigo não trataremos das condições em que o conhecimento supera, em certo sentido, o impulso da vontade, o que caracteriza o gênio artístico, e em termos éticos o caso do asceta.

${ }^{5}$ SCHOPENHAUER, A. P/P, § 4, p. 81, tradução nossa.

${ }^{6}$ SAFRANSKI, Schopenhauer e os anos mais selvagens da filosofia, p. 367.

7 SCHOPENHAUER, A. WWV II/ MVR II, cap. 20, p. 297.

8 Idem, cap. 20, p. 298.

Corpo, cognição e vontade: aproximação e distanciamento entre Schopenhauer e a teoria enativista
} 
próprio conhecimento, algo condicionado pelo cérebro; porém, é o prius do conhecimento, o núcleo do nosso ser e a força originária mesma que cria e mantém o corpo animal, na medida em que executa tanto as suas funções conscientes quanto inconscientes; - este é o primeiro passo no conhecimento profundo da minha metafísica9 .

Assim, todos os órgãos do nosso corpo seriam objetivações da vontade, e uma vez que esta se manifesta como Vontade de vida ${ }^{10}$, cada um deles cumpre alguma função para a manutenção do organismo. 0 filósofo sustenta uma espécie de hierarquia, uma divisão de competências no interior do nosso organismo: ao cérebro ficaria delegado o papel de "ministério do exterior"11, já que, sendo o órgão do conhecimento, e sendo o conhecimento um instrumento da vontade, o cérebro estaria incumbido de atender às circunstâncias favoráveis à sobrevivência do organismo, regulando sua relação com o mundo externo.

Para que o cérebro pudesse cumprir essa função foi que a natureza fez dele seu produto mais complexo. A gradação que observamos na natureza, partindo dos seres de constituição mais simples até o mais complexo, se observa também na constituição do organismo animal, e nesta gradação o cérebro é o órgão que representa o ápice de desenvolvimento da natureza. Nas palavras de Schopenhauer: "o cérebro é a florescência do organismo; por isso, só quando este alcança sua suprema perfeição e complexidade é que aquele entra em cena em seu pleno desenvolvimento" 12.

Portanto, a necessidade de se compreender a cognição como algo intrinsecamente ligado ao organismo aparece de forma marcante na filosofia de Schopenhauer, pois o mesmo reconhece que "a inteligência depende sempre do sistema cerebral, e este encontra-se em uma relação necessária com o restante do organismo"13. A cognição, assim, deve ser considerada como algo que trabalha em função da vida do organismo, pois como todas as outras funções corporais ela está subordinada ao pulso da Vontade.

Por conseguinte, também essa consideração mostra-nos a vontade como o originário e, portanto, metafísico, o intelecto, ao contrário, como algo secundário e físico. Pois, como tal, o intelecto, como tudo o que é físico está submetido à vis inertiae, portanto, só se torna ativo quando é

\footnotetext{
${ }^{9}$ Idem, cap. 23, p. 353.

${ }^{10} \mathrm{Cf}$. WWV I/ MVR I, $\S 54$.

11 Idem, cap. 19, p. 292.

12 Idem, WWV II/ MVR II, cap. 22, p. 333.

13 Idem, N/N, p. 103.

Corpo, cognição e vontade: aproximação e distanciamento entre Schopenhauer e a teoria enativista
} 
impulsionado por algo outro, pela vontade, que o domina, controla, estimula-o ao esforço, numa palavra, confere-lhe a atividade que originariamente não lhe é inerente ${ }^{14}$.

A concepção que estabelece o primado da vontade sobre o intelecto (enquanto faculdade cognitiva) é o que leva Schopenhauer a considerar o enfoque tradicional do problema mente-corpo como uma equivocada inversão da relação entre a vontade (princípio metafísico que se apresenta originariamente no organismo) e a cognição. Para Pedreira, a definição schopenhaueriana do intelecto como uma função fisiológica do cérebro, caracteriza “o cerne que ocasionou a ruptura realizada por Schopenhauer com a tradição filosófica ao mostrar o caráter temporal e ilimitado do intelecto, não mais entendido como eminentemente transcendental"15.

Assim, reconhecer a importância do corpo para o conhecimento do mundo implicaria recusar certa concepção "cognitivista"16, isto é, aquela concepção previamente assumida pela filosofia que postulava a vontade como uma mera função do intelecto. Esta recusa se dá justamente na medida em que passamos a considerar a mente como algo secundário em relação àquela força "que forma e mantém o corpo animal", isto é, a vontade, que é cega e inconsciente.

É possível afirmar, entretanto, que no debate acerca da relação ontológica entre mente e corpo a perspectiva denominada de "cognitivismo" ainda goza de ampla preponderância. Segundo Varela, Thompson e Rosch, "Referimo-nos a ele [cognitivismo] como o centro ou núcleo da ciência cognitiva porque ele domina a pesquisa em tamanha extensão que geralmente é simplesmente tomado como a ciência cognitiva em si mesma"17.

A postura cognitivista ganhou ainda mais força quando, a partir da segunda metade do século XX, foi formulado um modelo computacional para a mente humana, segundo o qual a mente pode ser comparada à atividade de um computador, no sentido de que ambos processam informação através da manipulação de símbolos, realizando internamente o processo de representar características do mundo. Segundo Thompson,

\footnotetext{
14 Idem, WWV II/ MVR II, cap. 19, p. 258.

15 PEDREIRA, A. L. S. Comentários sobre a concepção objetiva do intelecto em Schopenhauer a partir da leitura dos Complementos ao "Mundo como vontade e como representação", pp. 105-106.

16 É certo que o termo não é usado por Schopenhauer, no entanto, os enativistas afirmam que tal concepção remonta ao dualismo cartesiano, que é justamente o alvo da crítica de Schopenhauer.

17 VARELA, THOMPSON, ROSCH, The embodied mind: cognitive science and human experience, p. 8. (As traduções dos textos de Varela e Thompson citados neste artigo são nossas).

Corpo, cognição e vontade: aproximação e distanciamento entre Schopenhauer e a teoria enativista
} 
"de acordo com o modelo computacional da mente, o cérebro, também, é um computador, 'sistema de símbolos físicos,' e processos mentais são realizados através da manipulação de representações simbólicas no cérebro"18.

Ao afirmar que a cognição consiste num processo físico que ocorre em termos de códigos simbólicos, o modelo computacional de mente supõe uma separação entre dois níveis da atividade mental: um nível consciente, e outro que além de não ser consciente não pode tornar-se consciente, o que Dennet chama de "sub-personal level". Este último nível, inacessível à consciência, seria justamente a base da atividade computacional simbólica que perfaz o processo de representação, em relação ao qual não temos acesso, "uma vez que, presumivelmente, nenhum de nós tem qualquer consciência da computação como um médium simbólico interno quando nós pensamos"19.

Ao distanciar nossa atividade cognitiva da experiência corporal concreta, o cognitivismo reforçaria a ideia de que a pesquisa científica se configura "como um olho descorporificado olhando objetivamente para o jogo dos fenômenos" 20 . Procedendo deste modo a abordagem cognitivista ignora o quanto nossa atividade mental se integra ao funcionamento do organismo como um todo, e o quanto este funcionamento se dá numa interatividade circular com o ambiente, ou seja, numa experiência contínua e mútua entre mente (corporificada) e mundo, na qual nenhuma característica destes dois polos pode ser entendida de forma exclusiva e independente.

Em reação àquela concepção de ciência, a teoria conhecida como enativismo propõe que a "cultura científica ocidental requer que vejamos nossos corpos tanto como estruturas físicas quanto como estruturas experienciais vivas - em suma, tanto por "fora" como por "dentro", o biológico e o fenomenológico"21. Uma vez que o enativismo "põe o organismo e o corpo no centro do palco da ciência da mente" 22 , a busca pela compreensão da mente não pode prescindir de uma descrição da consciência, o que implica considerar a mente e os processos a ela atribuídos como algo experienciado no corpo, pois "eventos mentais não ocorrem em um vácuo, eles são vividos por alguém" 23 .

Em The embodied mind, os autores argumentam que o cognitivismo subestima o

${ }^{18}$ THOMPSON, E. Mind in life: biology, phenomenology, and the sciences of mind, pp. 4-5.

${ }^{19}$ VARELA, THOMPSON, ROSCH, The embodied mind: cognitive science and human experience, p. 49.

20 Idem, p. 4.

${ }^{21}$ Idem, p. xv.

${ }^{22}$ THOMPSON, E. Mind in life: biology, phenomenology, and the sciences of mind, p. 16.

${ }^{23}$ Idem, p. 16. Schopenhauer afirma que uma profunda significação do mundo só é possível ao sujeito porque este se enraíza no mundo como indivíduo, ou seja, ele não é uma "cabeça de anjo alada destituída de corpo" (Cf. § 18 do Tomo I de 0 mundo como vontade e como representação).

Corpo, cognição e vontade: aproximação e distanciamento entre Schopenhauer e a teoria enativista 
corpo enquanto contexto ou meio de mecanismos cognitivos. Para superar esta perspectiva, os autores elaboram a teoria enativista, que tem como uma de suas teses centrais a ideia de que "cognição é o exercício de um hábil saber-como em uma ação situada e corporificada. Estruturas e processos cognitivos emergem de padrões sensório-motores, recorrentes da percepção e da ação"24. Processos cognitivos não seriam de uma natureza diferente das outras atividades do organismo, isto é, não se tratam de duas instâncias ontologicamente diferentes. Neste sentido, a mente deve ser entendida como algo corpóreo; necessariamente integrada ao ambiente no e com o qual interage. Assim, na teoria enativista, a cognição não se limita à atividade cerebral, pois “seres vivos são agentes autônomos que ativamente geram e mantém a eles mesmos, e assim também promulgam (enact) ou produzem seus próprios domínios cognitivos”25. Aqui a noção de "domínios cognitivos" (cognitive domains) já se estende a todos os seres vivos (living beings), e, portanto, não pode ser circunscrita à experiência cognitiva decorrente ou dependente do cérebro humano.

Isto levará a teoria enativista a propor uma relação de continuidade entre mente (cognição) e vida. Neste ponto, além do viés fenomenológico, o enativismo toma como base a noção de autopoiesis ${ }^{26}$, termo que conceitua um tipo de "self-producing autonomy" característico dos seres vivos.

Em Life in Mind, Thompson defende a tese de que a característica essencial dos seres vivos é a de se constituírem como uma organização autopoiética, o que em nível biológico significa que "eles são organizados de tal forma que seus processos constituintes produzem os componentes necessários para a continuação daqueles mesmos processos"27. Constituindo-se enquanto sistema autônomo, cada ser vivo se configura como um sistema aberto, inserido num processo circular em que a produção dos componentes necessários para sua existência ocorre em interação com o ambiente, sendo que o que diferencia ambiente e organismo é a capacidade deste último de manter-se em processo de auto-produção, criando seu domínio cognitivo.

Cada organismo, nesta perspectiva, é entendido como uma unidade que

\footnotetext{
24 THOMPSON, E. Précis of Mind in Life: Biology, Phenomenology, and the Sciences of Mind, p.11.

25 Idem, p. 10-11.

26 Processo metabólico que ocorre nas células vivas a partir do qual surgem membranas semipermeáveis, constituindo as células enquanto unidades bioquímicas e determinando seu domínio de interações com o mundo (Cf. THOMPSON, E. STAPLETON, M. Making Sense of Sense-making, p. 24).

27 THOMPSON, E. Mind in life: biology, phenomenology, and the sciences of mind, p. 98.

Corpo, cognição e vontade: aproximação e distanciamento entre Schopenhauer e a teoria enativista
} 
estabelece sua identidade ao se autoproduzir, e neste processo (autopoiético) é preciso se levar em conta que, na busca de sua autoafirmação, o organismo estabelece um domínio de interações, isto é, estabelece uma rede de significados com o ambiente. Para Thompson:

A vida é, assim, um processo de autoafirmação que produz ou promulga (enact) sua própria identidade e dá sentido ao mundo a partir da perspectiva daquela identidade. A 'preocupação' do organismo, seu 'propósito natural', é manter-se ativo, continuar vivendo, afirmar e reafirmar a si mesmo em face do iminente não-ser ${ }^{28}$.

É no estabelecimento desta relação de cada organismo com seu ambiente que a teoria enativista compreende o laço necessário entre autonomia adaptativa e cognição; e é a partir da mesma que procuram sustentar a tese de uma profunda continuidade entre vida e mente. Um organismo, por mais simples que seja sua constituição, possuindo organização autopoiética e adaptividade já pode, em termos enativistas, ser considerado um ente portador de cognição. Assim, para Maturana:

Um sistema cognitivo é um sistema cuja organização define um domínio de interações no qual ele pode agir com relevância para a manutenção de si mesmo, e o processo de cognição é o real (indutivo) agir ou comportar-se neste domínio. Sistemas vivos são sistemas cognitivos e, viver, enquanto processo, é um processo de cognição. Esta declaração é válida para todos os organismos, com e sem um sistema nervoso ${ }^{29}$.

A cognição, portanto, seria um processo que ultrapassaria a mera atividade de representar características do mundo, cujo critério de demarcação seria não a existência de um sistema nervoso, mas sim a concretização de uma autonomia adaptativa que tornaria aquele organismo um "sense-making system". Thompson admite que o termo "cognição" é usado aqui de uma forma bem ampla, mas é este conceito de cognição que mostra, segundo o autor, o laço entre a forma de organização autopoiética, comum aos seres vivos, e a intencionalidade característica da consciência humana.

Autopoiesis, intencionalidade e cognição, no entanto, são todos conceitos que se ancoram e dependem da experiência corporal subjetiva; não pode haver uma adequada compreensão da mente, de acordo com o enativismo, numa investigação que negligencie

\footnotetext{
28 Idem, p. 153.
}

${ }^{29}$ MATURANA apud THOMPSON, E. Mind in life: biology, phenomenology, and the sciences of mind, p. 124.

Corpo, cognição e vontade: aproximação e distanciamento entre Schopenhauer e a teoria enativista 
a continuidade entre as perspectivas biológica e fenomenológica, pois para "fazer a ligação da matéria à vida e à mente, a partir da biologia e psicologia físicas, precisamos de conceitos tais como organismo e autopoiesis, mas esses conceitos são disponíveis somente para um sujeito num corpo, com experiência em primeira mão de sua própria vida, corporalmente"30.

A experiência imediata do próprio corpo é aqui apontada como algo fundamental para explicar a continuidade entre vida e mente, dado que este seria o ponto de partida para uma abordagem que suprimiria a separação entre mente e corpo, na medida em que ajudaria a "entender a relação entre o corpo como um ser vivo e o corpo como um corpo vivido, ou corporalmente sujeito da experiência"31, além do que daria base a uma concepção capaz de mostrar que a mente é mais do que simples manipulação de símbolos. De fato, com o enativismo teríamos de assumir que o conhecimento do mundo só ocorre como interação entre o ser, que se constitui como sistema autônomo, e o ambiente onde ele cria um domínio de significados necessários à sua manutenção, sem que haja necessariamente a manipulação de símbolos.

Assim, de acordo com o enativismo, a ideia de uma atividade cognitiva "corporificada" leva a uma aproximação entre as noções de "mente" e "vida", uma vez que, segundo a teoria da autopoiesis "natureza não é pura exterioridade, mas, ao invés disso, no caso da vida tem sua própria interioridade e, assim, assemelha-se à mente. Por outro lado, a mente não é pura interioridade, mas uma forma ou estrutura de engajamento com o mundo e, assim, assemelha-se à vida"32.

\section{Considerações finais}

Neste ponto a metafísica de Schopenhauer se mostra próxima da proposta enativista. Ainda que o pensador alemão afirme que o conhecimento é essencialmente representação, sua filosofia toma como tese fundamental a ideia de que o corpo é o objeto que unifica as dimensões externa e interna da nossa cognição. De acordo com ele, conhecemos nosso corpo de dois modos: "uma vez como representação na intuição do

\footnotetext{
30 Idem, p. 164.

31 THOMPSON, E. Précis of Mind in Life: Biology, Phenomenology, and the Sciences of Mind. IN:- Journal of consciousness studies, 2011, p. 8.

32 Ibidem, p. 4.

Corpo, cognição e vontade: aproximação e distanciamento entre Schopenhauer e a teoria enativista
} 
entendimento, como objeto entre objetos e submetido às leis destes; outra vez de maneira completamente outra, a saber, como aquilo que é conhecido imediatamente por cada um e indicado pela palavra Vontade"33.

No entanto, para Schopenhauer, mais que um processo decorrente ou dependente de um sistema nervoso, a vontade, que produz também a experiência subjetiva, é antes de tudo "esse substrato de toda aparição (e, com isso, de toda natureza)" e que:

longe de, como supunham todos os filósofos até agora, ser inseparável da cognição e mesmo um mero resultado da mesma - dela, que é totalmente secundária e tardia -, é fundamentalmente distinta e plenamente independente desta, e que consequentemente essa vontade pode também existir e se manifestar sem ela, o que é realmente o caso em toda natureza, dos animais para baixo; que essa vontade (...) fornece a todas as coisas, quaisquer que venham a ser, a força graças à qual elas podem existir e atuar ${ }^{34}$.

A tese que distingue cognição e vontade, sugerida aqui, nos remete a alguns críticos da teoria enativista, que põem em xeque a ideia de que a autopoiesis implica necessariamente cognição. Para eles, "Todos os sistemas vivos são sistemas tanto autopoiéticos como cognitivos, mas um sistema autopoiético não é necessariamente um sistema cognitivo"35. Levando esta crítica em consideração, seria ainda possível estabelecermos uma relação entre vida e cognição, no entanto tal relação tornar-se-ia mais complexa, já que autopoiesis não garantiria por si só um estatuto cognitivo. Seres cognoscentes constituiriam um conjunto mais restrito, ao passo que o conjunto dos seres autopoiéticos seria mais amplo. Por sua vez, é sabido que para Schopenhauer o intelecto, responsável pela cognição, é mero acidente do organismo, ou seja, não é algo essencial para os entes, ao passo que a Vontade seria o substrato verdadeiro de todos eles.

A vontade, como coisa em si, constitui a íntima, verdadeira e indestrutível essência do ser humano: porém, em si mesma é sem consciência. Pois a consciência é condicionada pelo intelecto, e este é um mero acidente do nosso ser, visto que se trata de uma função do cérebro que, junto com os nervos e a medula espinhal a ele anexados, é um mero fruto, um produto, sim, em verdade um parasita do restante do organismo, na medida em que não intervém diretamente em sua maquinaria interna mas tão somente serve ao fim da autoconservação,

${ }^{33}$ SCHOPENHAUER, A. WWV I/ MVR I, § 18, p. 157.

${ }^{34}$ SCHOPENHAUER, A. N/N, p. 44-45.

35 THOMPSON, E. Mind in life: biology, phenomenology, and the sciences of mind, p. 124.

Corpo, cognição e vontade: aproximação e distanciamento entre Schopenhauer e a teoria enativista 
regulando a relação do organismo com o mundo exterior ${ }^{36}$.

Sabemos que a noção de Vontade em Schopenhauer possui uma maior profundidade ontológica do que a de autopoiesis, o que nos leva a considerar aqueles seres autopoiéticos, no máximo, como meras objetivações particulares da Vontade. No entanto, uma vez que esta permanece como substrato da natureza, e que não é possível pensar a noção de vida (Leben) sem situá-la no contexto de objetivação da Vontade, o processo de autopoiesis parece situar-se também no mesmo contexto. Além do que, como afirma Soria:

A organização do corpo vivo não está em uma parte do ser (no cérebro ou no coração, por exemplo), ou em um princípio ou força que reside em uma parte do organismo (no sistema circulatório, por exemplo); ao contrário, está generalizada em todas as partes que compõem o corpo ${ }^{37}$.

Sendo a autopoiesis uma característica fundamental dos seres vivos (que se autoproduzem em interação com o ambiente a fim de manterem sua organização e funcionamento), não haveria então aqui uma proximidade com o conceito schopenhaueriano de Vontade de vida? E neste sentido, a noção de mente, ou cognição (comum a todos os seres vivos) que a teoria enativista propõe não se aplicaria mais adequadamente aos entes capazes de agirem por excitações e motivos (segundo a classificação de Schopenhauer)? As perguntas ficam em aberto. É certo que a hipótese de uma compatibilização entre a metafísica de Schopenhauer e as teses enativistas acerca da mente exige um exame muito mais aprofundado, já que, embora as noções de Vontade de vida e autopoiesis guardem algumas semelhanças, parece improvável que o pensamento schopenhaueriano admita como cognoscentes os seres que agem estritamente por excitação. De todo modo, é possível notar que tanto a metafísica da Vontade como a teoria enativista apontam, cada uma ao seu modo, para a necessidade de uma reconsideração do conceito de cognição.

\section{Referências bibliográficas}

${ }^{36}$ SCHOPENHAUER, A. WWV II/ MVR II, cap. 19, p. 243.

37 SORIA, A. C. S. Orgânico e inorgânico em "Sobre a vontade na natureza", p. 200.

Corpo, cognição e vontade: aproximação e distanciamento entre Schopenhauer e a teoria enativista 
PEDREIRA, A. L. S. Comentários sobre a concepção objetiva do intelecto em Schopenhauer a partir da leitura dos Complementos ao Mundo como vontade e como representação. Revista Voluntas: Estudos sobre Schopenhauer, Rio de Janeiro, Vol. 4, № 1, 2013, pp. 98-113.

SAFRANSKI, R. Schopenhauer e os anos mais selvagens da filosofia. Trad. William Lagos. São Paulo: Geração Editorial, 2011.

SCHOPENHAUER, A. De la quadruple racine du principe de raison suffisante. Présentation, traduction et notes par François-Xavier Chenet. 2 ed. Paris: Vrin, 2008. 2005 O mundo como vontade e como representação. Tomo I. Trad. Jair Barboza. São Paulo: Unesp,

. O mundo como vontade e como representação. Tomo II. Trad. Jair Barboza. São Paulo: Unesp, 2015.

. Parerga y Paralipómena I. Traducción, introducción y notas de Pilar López de Santa María. Madrid: Editorial Trotta, 2009.

. Parerga y Paralipómena II. Traducción, introducción y notas de Pilar López de Santa María. Madrid: Editorial Trotta, 2009.

Sobre a vontade na natureza. Trad. Gabriel Valladão Silva. Porto Alegre: L\&PM, 2013.

SORIA, A. C. S. Orgânico e inorgânico em "Sobre a vontade na natureza". Revista Voluntas: Estudos sobre Schopenhauer, Rio de Janeiro, Vol. 3, №s 1 e 2, 2012, pp. 195-202.

TEIXEIRA, J. de F. Filosofia do cérebro. São Paulo: Paulus, 2012.

THOMPSON, E. STAPLETON, M. Making sense of Sense-Making: Reflections on enactive and extended mind theories. Springer Science+Business Media, 2008, pp. 22-30.

THOMPSON, E. Mind in life: biology, phenomenology, and the sciences of mind. Cambridge: The Belknap Press of Harvard University Press, 2007.

Précis of Mind in Life: Biology, Phenomenology, and the Sciences of Mind. Journal of consciousness studies, 18, No 5-6, 2011, pp 1-13.

VARELA, F. J., THOMPSON, E.; ROSCH, E. The embodied mind: cognitive science and human experience. Cambridge: MIT Press, 1993.

Recebido: 03/09/16 Received: 09/03/16

Aprovado: 04/11/16

Approved: 11/04/16 